\title{
Pedagogia crítico-superadora e o modelo pendular. uma aproximação necessária para o ensino dos esportes coletivos na escola
}

\section{Critical-overcoming pedagogy and the pendular model: a necessary approximation for the teaching of collective sports in school}

\author{
1 Renan Santos Furtado renan.furtado@yahoo.com.br \\ 1 Libório Lúcio Amorim Barreto \\ 1 Adso Haydemar Ferreira Ramos
}

1 Universidade Federal do Pará - UFPA

\section{Resumo}

Neste ensaio, buscamos apresentar possibilidades teórico-práticas para o ensino dos esportes coletivos. Nosso escrito pode ser caracterizado como uma produção bibliográfica. Em relação aos nossos objetivos, pretendemos apresentar uma abordagem conceitual histórica do esporte, analisar as proximidades e possibilidades do modelo pendular se articular com a pedagogia crítico-superadora e rediscutir a função da técnica na Educação Física escolar, assim como apontar aspectos de uma pedagogia do esporte que considere a técnica como elemento da cultura e não como meio para docilizar corpos. Concluímos que a proposta de Bayer, explicitada por Daolio, pode proporcionar uma apreensão diferente das técnicas esportivas em relação às formas tradicionais e tecnicistas. Tendo essa base fundamental, o estudante poderá praticar e entender as diversas modalidades, desenvolvendo tanto valências/qualidades físicas quanto uma concepção crítica do fenômeno esportivo.

\section{Palavras-chave:}

Pedagogia crítico-superadora. Esporte coletivo. Modelo pendular.

\begin{abstract}
In this essay we seek to present theoretical-practical possibilities for teaching collective sports. Our writing can be characterized as a bibliographical production. In relation to our objectives, we intend to present a historical conceptual approach to the sport, to analyze the proximity and possibilities of the pendular model to articulate with the critical-overcoming pedagogy, and to rediscuss the function of technique in Physical School education, as well as to point out aspects of a pedagogy of sports that considers technique as an element of culture, and not as a means to docilize bodies. We conclude that the proposal of Bayer, made explicit by Daolio, can provide a different apprehension of the sports techniques in relation to the traditional and technicist forms. Having this fundamental basis, the student will be able to practice and understand different modalities, developing both physical qualities and a critical conception of the sporting phenomenon.
\end{abstract}

\section{Keywords:}

Critical-overcoming. Pedagogy team sport. Pendular model.

\section{Como você deve citar?}

FURTADO, Renan Santos; BARRETO, Libório Lúcio Amorim; RAMOS, Adso Haydemar Ferreira. Pedagogia crítico-superadora e o modelo pendular: uma aproximação necessária para o ensino dos esportes coletivos na escola. Cadernos UniFOA, Volta Redonda, n. 40, p.83-94, agosto 2019. 
Pedagogia crítico-superadora e o modelo pendular:

uma aproximação necessária para o ensino dos esportes coletivos na escola

\section{INTRODUÇÃO}

O esporte é um dos fenômenos que caracteriza a forma de ser modernidade, pois, uma série de características do nosso mundo se encontra presente nas práticas esportivas. Todavia, o fato do esporte ser tão difundido como fenômeno humano não garante que ele seja compreendido pelos sujeitos. Como afirma Bourdieu (2004), existe uma tendência de algumas pessoas saberem muito sobre o esporte e de outras saberem exclusivamente praticar os esportes. Contudo, para o sociólogo francês, a tarefa de uma pedagogia do esporte é justamente realizar a mediação entre o conhecimento do esporte como fenômeno social e a sua aprendizagem na forma de experiência corporal.

$\mathrm{Na}$ área da Educação Física, historicamente, a dimensão técnica do esporte gozou de certo privilégio. Além disso, pode-se constatar, principalmente desde a segunda metade do século XX, no Brasil, a existência de um uso instrumental e exacerbado dos elementos técnicos do esporte com o intuito de dominar os indivíduos e formá-los para o campo produtivo (BRACHT, 1986; CASTELLANI FILHO, 1993).

Nesse sentido, o presente trabalho busca propor que a utilização da estrutura pendular de ensino dos esportes coletivos, desenvolvida por Claude Bayer, Oliveira e Graça e Julio Garganta, que foi sintetizada e explicitada a partir da leitura de Daolio (2002), seja pensada e incorporada pela pedagogia crítico-superadora, desenvolvida, inicialmente, pelo Coletivo de autores (2012). Partindo da análise de textos-base dessas pedagogias, faremos uma pesquisa bibliográfica, para, posteriormente, apontarmos nossas considerações a respeito da discussão em questão.

Tal aproximação ocorre por intermédio da identificação do objetivo proposto pelas duas pedagogias na mediação do ensino dos esportes coletivos, que a nosso ver são convergentes, pois ambas se contrapõem ao modelo baseado na aptidão física e do ensino das técnicas esportivas de forma fragmentada nas aulas de Educação Física. Segundo o Coletivo de Autores $(2012)$, Kunz $(1991 ; 1994)$ e Bracht (1997), os modelos baseados no desenvolvimento da aptidão física por via do esporte foram e são hegemônicos nas aulas de Educação Física e princípios como seletividade e desempenho ainda se fazem presentes, assim como à supervalorização do ensino do movimento nos padrões do esporte de alto rendimento.

A pedagogia crítico-superadora, desenvolvida e exposta inicialmente pelo Coletivo de Autores (2012), busca a assimilação e a compreensão dos conteúdos da cultura corporal (jogo, esporte, dança, ginástica, luta etc.) pelos estudantes, de forma que eles possam ter acesso a esses saberes de modo crítico e emancipatório, para, desse modo, terem esclarecidas as múltiplas relações que acontecem entre essas práticas corporais e a realidade social.

Já o modelo pendular, se contrapõe à ideia de ensino dos esportes coletivos primordialmente pelo ensino dos gestos técnicos. Nesse modelo, o estudante vai entender seu papel no jogo, que vai além da simples execução perfeita da técnica. Bayer e os demais formuladores dessa pedagogia do esporte identificaram a existência de invariantes nos jogos coletivos, ou seja, os esportes coletivos apresentam uma estrutura fixa com características semelhantes que acabam por direcionar o jogo, fazendo com que a técnica não seja o principal elemento a ser ensinado na aula.

Dessa forma, o que estamos propondo é que o modelo pendular seja um instrumento do professor dentro da abordagem crítico-superadora para a mediação das técnicas e das bases estruturais dos esportes coletivos. Destarte, traçamos três objetivos para esse ensaio. 0 primeiro perpassa pela apresentação de uma abordagem conceitual e histórica do esporte. 0 segundo circunda pela tarefa de analisar as proximidades e as possibilidades do modelo pendular ser utilizado em articulação com a pedagogia crítico-superadora. Por último, intencionamos rediscutir a função da técnica na Educação 
Física escolar, assim como apontar aspectos de uma pedagogia do esporte que considere a técnica como elemento da cultura e não como meio para docilizar corpos.

\section{METODOLOGIA}

Nosso escrito pode ser caracterizado como uma produção bibliográfica. Segundo Gil (2002, p. 44), a pesquisa bibliográfica é "desenvolvida com base em material já elaborado, constituídos principalmente de livros e artigos científicos". Com base em Severino (2002), podemos classificar este estudo como exploratório em relação aos seus objetivos, pois, nessa etapa, buscamos recolher informações sobre determinado objeto e confrontá-las com literaturas básicas, sem necessariamente criarmos teses ou regularidades científicas sobre o tema estudado.

Por intermédio de aproximação com a perspectiva dialética, exposta em suas bases por Marx e Engels (2007), Marx (2008; 2013) e Adorno (1995; 2013), apresentaremos uma reflexão crítica sobre a necessidade da pedagogia crítico-superadora se apropriar de propostas teóricas que apontem possibilidades para o ensino dos esportes coletivos. Tendo em vista que o ensino do esporte escolar teve sua trajetória marcada pelos valores do rendimento, acreditamos que essa proposta traz uma perspectiva que difere da lógica hegemonicamente construída, podendo ser incorporada por professores da educação básica, centros esportivos, espaços de lazer e cursos de formação de professores.

Sendo assim, a seguir, continuaremos nossas reflexões e proposições em dois momentos. No primeiro, buscaremos conceituar e caracterizar o fenômeno esportivo, assim como apontar a base teórica que defendemos para sua inserção na escola. Em seguida, discutiremos as possibilidades de utilização do modelo pendular nas aulas de Educação Física, tendo em vista o ensino dos esportes coletivos.

\section{ESPORTE E CULTURA CORPORAL: UMA ABORDAGEM HISTÓRICA}

Nesse tópico, buscaremos conceituar o fenômeno esportivo a partir da consideração de que tal prática social se funda em um momento específico da história da humanidade. Assim como, discutiremos as aproximações dessa abordagem do esporte com a perspectiva da pedagogia da cultura corporal.

A defesa de uma conceituação histórica do esporte no campo da Educação Física polemiza com autores como Kunz (1994) e Tubino (2011). Em síntese, para esses autores, o esporte sempre esteve presente na história da humanidade, pois todas as atividades competitivas que envolviam o movimento corporal poderiam ser caracterizadas como práticas esportivas. Kunz (1994) parece adentrar ainda mais em armadilhas relativistas, quando afirma que o esporte, em sentido amplo, deve abarcar as práticas do cotidiano do mundo vivido dos sujeitos. Desse modo, caminhar e andar de bicicleta poderiam ser considerados como práticas esportivas e constitutivas da cultura de movimento do ser humano.

A nosso ver, tal concepção não demarca o momento histórico que a prática esportiva se funda e tampouco consegue realizar amplas reflexões sobre a prática dos esportes e os tipos de sociedades nas quais ele se desenvolvia. Assim, estabelece uma relação natural entre o ser humano e a prática do esporte, baseada na ideia de que, desde que existe homem, ele se movimenta e, por consequência, pratica esporte de algum modo em sua interação com o meio natural.

Nessa abordagem, o esporte passa a ser estudado por etapas ao longo da história, existindo o esporte na antiguidade até o esporte moderno. É justamente em oposição a essa concepção de es- 
Pedagogia crítico-superadora e o modelo pendular:

uma aproximação necessária para o ensino dos esportes coletivos na escola

porte que, na Educação Física, autores como Assis de Oliveira (2001), Bracht (2005) e Stigger (2005) elaboraram instigantes teses sobre o esporte moderno, ou melhor, sobre o esporte.

Stigger (2005) apresenta, a partir de Thomas (1991), duas conhecidas teses sobre a gênese do esporte difundidas nos meios acadêmicos da área, sendo elas, a da continuidade e a da ruptura. Em suma, os defensores da tese da continuidade, com os representantes apresentados acima, advogam que todas as atividades corporais desenvolvidas no decorrer da história até os nossos dias constituem as práticas esportivas. Em contrapartida, a tese da ruptura, defendida enfaticamente também por Ellias e Dunning (1992), afırma que o fenômeno esportivo se funda na transição industrial da Europa, nos séculos XVIII e XIX, sendo resultado de um processo de apropriação e de superação dos jogos realizados tanto pelas elites (aristocratas), como pelas camadas populares da Inglaterra. Nas palavras de Bourdieu (1978) ${ }^{2}$,

\begin{abstract}
parece indiscutível que a passagem do jogo ao esporte propriamente dito tenha se realizado nas grandes escolas reservadas às "elites" da sociedade burguesa, nas public schools inglesas, onde os filhos das famílias da aristocracia ou da grande burguesia retomaram alguns jogos populares, isto é, vulgares, impondo-lhes uma mudança de significado e de função muito parecida àquela que o campo da música erudita impôs às danças populares, bourrées, gavotas e sarabandas, para fazê-las assumir formas eruditas como a suíte. (BOURDIEU, 1978, p. 4).
\end{abstract}

Bourdieu (1978) identifica que ocorreram mudanças no sentido dos jogos praticados nessa época (sempre relacionados com festividades ou acontecimentos do dia a dia), pois, a partir de então, o esporte passou a ser praticado seguindo valores da nova sociedade que se formava. A escola, local para os filhos da elite e construída para disponibilizar atividades de formação do estilo de vida burguês, cumpriu um papel fundamental na institucionalização dessas práticas corporais, afastando-as das suas motivações originais. Nesse sentido, a escola apresenta uma função hedonista e despreocupada, difundindo essa prática não somente na esfera do esporte, mas também para outros campos, como o da arte, das linguagens e etc. ${ }^{3}$

Em Hobsbawm (2015), encontramos uma fonte fulcral para a compreensão do fenômeno esportivo nascido na Inglaterra industrial por via de uma matriz histórica e de ampla relação com os processos sociais das revoluções burguesas. Por meio desse autor, queremos pensar o esporte dentro do bojo daquilo que o historiador denomina de tradição inventada, que, segundo ele,

por "tradição inventada" entende-se um conjunto de práticas, normalmente reguladas por regras tácida ou abertamente aceitas; tais práticas, de natureza ritual ou simbólicas, visam inculcar certos valores e normas de comportamento através da repetição, o que implica, automaticamente, uma continuidade em relação ao passado. Aliás, sempre que possível, tenta-se estabelecer continuidade com um passado histórico apropriado (HOBSBAWM, 2015, p. 8).

Hobsbawm (2015) nos apresenta um ponto de vista extremamente singular para pensarmos o desenvolvimento das práticas esportivas na Inglaterra, como uma tradição inventada e forjada intencionalmente por parte dos grupos dominantes, pois, para o autor em questão, tais atividades fazem

2 É interessante quando analisamos o desenvolvimento das práticas corporais a partir do confronto entre as formas tradicionais de determinada atividade com as novas nuances ou tradições que adentram nas práticas realizadas do mundo moderno. Exemplo disso, podemos encontrar em Bregolato (2000) e Ayoub (2003). No primeiro escrito, a autora demonstra como as danças modernas e tidas como clássicas entraram em confronto e incorporaram elementos das danças folclóricas, religiosas e outras manifestações típicas das diferentes e antigas formas de organização social. Já em Ayoub (2003), o debate é sobre como a ginástica francesa se apropriou da ampla gama de movimentos e da estética das manifestações circenses dos artistas de rua, racionalizando expressões da própria cultura popular e dando a tais expressões contornos de cientificidade, tornando as práticas corporais cada vez mais alinhadas com a forma moderna de viver.

3 Em Bourdieu e Passeron (2014), o leitor encontrará subsídios para compreender a face de reprodução das estruturas sociais e da cultura capitalista presente na escola moderna. 
parte daquilo que a tradição marxista chama de superestrutura de uma sociedade se caracterizando pela difusão da ideologia de um determinado grupo social. ${ }^{4}$

Parece existir afinidade entre a ideia de Hobsbawm e os apontamentos de Bourdieu sobre o reconhecimento da mudança histórica que certas atividades perpassam para suplantar determinados interesses. Nesse caso, trata-se da transformação do esporte como a forma institucionalizada dos jogos ou passatempos populares. Tal fato é implicitamente coadunado por Hobsbawm (2015), quando o autor elucida as transformações que o campeonato de futebol britânico passou para condizer com as necessidades da nova sociedade, deixando evidente o sentido do futebol e por consequência das práticas esportivas dentro do bojo das tradições que se incorporam ao cotidiano das pessoas, de tal modo que dificilmente as massas populares são capazes de explicar a origem e muito menos o sentido daquilo que, muitas vezes, cultuam e reproduzem na esfera da cultura.

O estabelecimento dessa abordagem histórica do esporte como forma de compreensão desse fenômeno aponta para a demanda de análise da evolução dele em cada etapa do desenvolvimento da humanidade, assim como sugere a necessidade da identificação de suas relações e condicionantes sociais, culturais e políticas e quais foram as implicações dessas transformações para a Educação Física escolar. Por exemplo, se analisarmos o esporte no século XX, perceberemos a grande difusão desse fenômeno social pelo mundo, principalmente a datar da segunda metade desse século, a partir da disseminação dos grandes manifestos e documentos internacionais do esporte (TUBINO, 2011). ${ }^{5}$

Bracht $(1997 ; 2014)$ é fundamentalmente crítico em relação ao uso social do esporte nas instituições brasileiras. Para o autor, quando o esporte se consolida no Brasil, acaba reproduzindo nas instituições escolares o modelo do esporte de rendimento, ou seja, da seleção em lugar da inclusão e do desempenho em detrimento do prazer e da participação crítica e reflexiva. Assim, a partir do momento em que o movimento ou os movimentos renovadores da Educação Física da década de 80 se colocaram a discutir os rumos que a área necessitava tomar para a superação do modelo tradicional de educação e de produção do conhecimento, o esporte foi também alvo considerável dessas elaborações (BRACHT, 2017).

O trabalho de Bracht (1997), que é resultado de uma série de estudos anteriores, pode ser apreciado como um dos escritos que elucida de forma precisa qual era o sentido da crítica tanto no campo macro da Educação Física, como também em relação ao fenômeno esportivo e a sua subordinação aos códigos sociais do mundo do capital. Nesse trabalho, o autor denuncia a valorização excessiva dos valores do mundo capitalista presentes nas práticas esportivas dentro e fora da escola, como, por exemplo, o incentivo da competitividade e da seletividade nas práticas esportivas, que, por diversas vezes, foram promulgadas por políticas de Estado e pelas instituições esportivas, principalmente no decorrer da segunda metade do século XX, no Brasil.

O importante é identificarmos que a área da Educação Física produziu conhecimento e proposições em relação a esse cenário. Não podemos negar ou abster da história o fato de que, na década de 80, o Brasil passava por um intenso processo de redemocratização e de abertura das discussões

4 O estudo e a interpretação do esporte como fenômeno social e político por via de abordagens das ciências sociais foi algo realizado por ilustres pensadores do século XX. Nesse sentido, em Adorno (1995; 1996), o esporte aparece como elemento da indústria cultural e mecanismo de semiformação e de alienação das massas. Em Gramsci (1991), o esporte é classificado como um aparelho privado de hegemonia. Em Althusser (1980), o esporte é elencado como um dos aparelhos ideológicos do Estado.

5 A Carta Internacional de Educação Física e Desportos da UNESCO, de 1979, pode ser considerada como um grande marco para o reconhecimento do esporte enquanto fenômeno social. Nesse documento, o conceito de esporte foi elaborado tendo vista suas dimensões para além do rendimento, como, por exemplo, o lazer e a educação. 
Pedagogia crítico-superadora e o modelo pendular:

uma aproximação necessária para o ensino dos esportes coletivos na escola

políticas, sociais e culturais restritas e coagidas pelos governos militares. Assim, a área da Educação Física começou a elaborar suas novas sínteses no enredo dessa trama (GHIRALDELLI, 1991).

Para a Educação Física escolar, surgiram, no final da década 80 e transcorrer dos anos 90, aquilo que a tradição da área vem denominando de abordagens de pedagógicas. ${ }^{6}$ Tais abordagens, em geral, apontam também concepções de esporte, assim como sugerem indicativos sobre sua forma de ensino na prática pedagógica nas escolas. Como sinalizamos desde a introdução deste escrito, apontamos a pedagogia da cultura corporal como uma perspectiva avançada para a Educação Física escolar, por acreditarmos que ela, além de, no plano teórico, se mostrar coerente na relação entre o conhecimento a ser tratado e os procedimentos metodológicos adotados, também apresenta uma noção de esporte avançada e ancorada na perspectiva histórica e social que defendemos acima.

Segundo o Coletivo de Autores (2012), a Educação Física é uma disciplina curricular que tematiza pedagogicamente na escola a área de conhecimento denominada de cultura corporal. Tal campo do saber, apresenta-se a partir de temas ou atividades corporais peculiares produzidas pelo homem. Logo, o jogo, o esporte, a ginástica, a dança, a luta e as demais manifestações corporais, nessa concepção, são compreendidos como produções culturais que os indivíduos precisam assimilar para se humanizarem, nas palavras de Gramsci (1990) e Saviani (2011), para formar parte de sua segunda natureza.

Em suma, a Educação Física escolar trata da expressão corporal como forma de linguagem apropriada pelo homem a partir de sua disponibilidade para o lúdico, o artístico, o agonístico e o estético. A expressão corporal e a linguagem do corpo expressas pelas práticas corporais acima citadas constituem o campo de conhecimento que a Educação Física deve pedagogizar, dosar e sequenciar no tempo e espaço da educação escolar.

Gamboa (2010) contribui nessa linha de reflexão histórica e ontológica da Educação Física, quando afirma que a natureza dela, como um tipo específico de educação, é de um trabalho não material, no qual o seu produto se apresenta no processo da atividade, ou seja, no ato de jogar, nadar, dançar, brincar etc. Dessa forma, essa cultura corporal humana deve ser compreendida no seu processo de produção e reprodução social em realidades que são historicamente determinadas, e também em sua forma educacional nas instituições de ensino.

Podemos dizer que o homem necessita se apropriar da cultura corporal para conhecer parte de sua própria humanidade, ou melhor, da sua cultura expressa na simbologia das práticas físicas do movimento humano. Souza (2009) afirma que a expressão corporal dos homens precisa ser tratada de maneira que o sujeito consiga se compreender e visualizar a realidade por via de uma perspectiva histórica e social.

Dessa forma, o esporte nessa concepção precisa ser compreendido e estudado como prática social objetivada e apropriada no devir da existência humana em sua construção histórica, logo, como parte do gênero humano (SOUZA, 2009). Desse ponto de vista, se considerarmos o esporte como condicionado historicamente pelas estruturas sociais que o fundam, o esporte escolar, em uma perspectiva crítico-superadora, deve problematizar questões que transcendam os próprios gestos técnicos, assim como ensinar tais gestos de forma que superem a reprodução do fazer pelo fazer.

6 Campos (2011) rediscute esse cenário histórico da Educação Física e problematiza algumas questões costumeiramente debatidas na área, como, por exemplo, o uso de terminologias, como abordagem, concepção e tendência na Educação Física. Acreditamos que essa leitura é uma contribuição significativa para o aprofundamento dessa discussão. 
De acordo com o Coletivo de Autores (2012), sendo o esporte uma produção histórico-cultural, ele se expurga também das formas da sociabilidade capitalista. Assim, princípios, como o da normatização, da competição exagerada, da racionalização dos meios técnicos e da exaltação do desempenho individual, precisam ser problematizados e superados dentro da prática pedagógica cotidiana nas escolas.

Reis et al. (2013) reafirmam que o esporte deve ser "alvo" de uma leitura crítica, para assim, seguir o bojo da reflexão social da cultura corporal. Todavia, os autores sinalizam dialeticamente o aspecto da possível superação da forma de esporte deturpado tal qual conhecemos atualmente. Para tal, o olhar sobre o fenômeno esportivo deve considerar sua face de produção humana e de elemento da cultura universal, sendo um possível instrumento para a crítica a todas as manifestações de opressão na educação e nas outras esferas das relações sociais.

Feitas tais considerações sobre o esporte e a pedagogia crítico-superadora, caminharemos, tendo em vista a aproximação com outra construção teórica, com o intuito de apresentarmos uma possibilidade para o ensino das técnicas esportivas, dimensão que consideramos essencial nesse fenômeno. Como afirmamos, o esporte escolar necessita dar conta da dimensão histórica de sua prática, de seus aspectos culturais e sociais em cada sociedade, assim como deve demonstrar as possibilidades à aprendizagem dos movimentos e gestos mais avançados que a humanidade produziu em cada prática esportiva. Nesse sentido, é justamente sobre essa última dimensão que centraremos nossa atenção a seguir.

\section{FUNDAMENTOS PARA A APROXIMAÇÃO}

Nesse momento, aprofundaremos pontos importantes das concepções em questão, em que ficarão evidentes as justificativas e as possibilidades da utilização dessas duas pedagogias de forma conjunta no ensino dos esportes coletivos. Ressaltamos que a reflexão realizada foi eminentemente a partir do ponto de vista operacional e das convergências entre as duas pedagogias e não decorrente de conexões epistemológicas ou ético-políticas. Desse ponto de vista, o sentido é pensar o caráter inacabado da pedagogia crítico-superadora e sua necessidade de incorporação das formas e metodologias mais avançadas para o ensino de cada conteúdo da Educação Física. Portanto, pensamos o modelo pendular, exposto por Daolio (2002), como uma possibilidade concreta para o ensino dos esportes coletivos.

Nas perspectivas educacionais, tradicional e tecnicista, o esporte se ancora principalmente em aspectos "biológicos para educar o homem forte, ágil, apto, empreendedor, que disputa uma situação social privilegiada na sociedade competitiva de livre concorrência: a capitalista" (COLETIVO DE AUTORES, 2012, p. 24), ou seja, nessa perspectiva, a Educação Física serve para desenvolver a aptidão física do estudante, sendo ele considerado como um futuro trabalhador produtivo.

Daolio (2002) afirma que, nessas tradições de ensino do esporte, praticar determinada modalidade significa saber fazer e dominar os gestos técnicos que a constituem. Desse modo, o ensino dos fundamentos e das técnicas é realizado de forma fragmentada e por etapas, não tendo o aluno contato com situações de jogo, até que domine a conduta motora de cada fundamento básico. ${ }^{7}$

Em vista disso, tais perspectivas tradicionais de ensino do esporte introduzem conceitos, valores, ideias que servem para legitimar a concepção de mundo burguesa no estudante, tais como a obedi-

7 Por exemplo, em uma pedagogia tecnicista, o aluno somente jogará o Futsal em si, quando dominar o passe, a recepção, a condução, a finalização etc. 
Pedagogia crítico-superadora e o modelo pendular:

uma aproximação necessária para o ensino dos esportes coletivos na escola

ência, o respeito às regras e a hierarquia. Nesse sentido, o modelo pendular pode auxiliar o processo de contraposição desses valores, na medida em que o jogar bem não seria apenas executar de forma eficiente um conjunto de técnicas, mas, além disso, contribuir de forma cooperativa e inteligente para o sucesso do empreendimento coletivo. No trecho a seguir, Daolio apresenta de forma geral a definição dessa pedagogia.

A intenção desse modelo é mostrar que, como um pêndulo em balanço, os princípios operacionais, na sua base,
realizam um movimento menor do que na sua extremidade, onde se localizam os gestos técnicos. Em outras
palavras, os mesmos princípios operacionais do Esporte Coletivo, definidos por Claude Bayer, serão necessários
pra a compreensão e prática das várias modalidades esportivas por parte do aluno, devendo ser enfatizados, ainda
que de forma não exclusiva, nos primeiros momentos do processo de ensino-aprendizagem (DAOLIO, 2002, p. 102).

Desse modo, considerando as diversas modalidades esportivas dentro de uma lógica, o que "as tornam passíveis de um mesmo tratamento pedagógico para seu ensino" (DAOLIO, 2002, p. 100), a base desse modelo se encontra no pressuposto de que os esportes coletivos apresentam seis invariantes: "uma bola (ou instrumento similar), um espaço de jogo, parceiros com os quais se joga, adversários, um alvo a atacar (e, de forma complementar, um alvo a defender) e regras específicas." (DAOLIO, 2002, p. 100). A partir daí, foram definidos seis princípios operacionais, passando por regras de ação e, por último, os gestos técnicos. Os princípios operacionais são divididos em três de ataque e três de defesa, de acordo com Daolio (2002).

Os três princípios operacionais de ataque são: conservação individual e coletiva da bola, progressão da equipe e da bola em direção ao alvo adversário e finalização da jogada, visando à obtenção de ponto. Os três princípios operacionais da defesa são: recuperação da bola, impedir o avanço da equipe contrária e da bola em direção ao próprio alvo e proteção do alvo visando impedir a finalização da equipe adversária (DAOLIO, 2002, p. 100).

As regras de ação são os meios para a operacionalização dos princípios, ou seja, mecanismos para alcançar o objetivo do jogo. Podemos citar, como exemplo, fazer "tabelas", se desmarcar, perceber e se deslocar para o ponto futuro, no qual a bola chegará. Nessa pedagogia, a técnica é definida como o "modo de fazer" e a tática são "as razões do fazer", assim, o gesto técnico se justifica por uma exigência natural do jogo. Por exemplo, uma finalização de cabeça no futebol (princípio operacional) requer treinamento (melhorar a técnica), concluindo o objetivo e, nesse sentido, técnica e tática não existem uma sem a outra. Nessa via de análise, Daolio (2002) comenta que,

com a abordagem de técnica (o como fazer) aliada à tática (as razões do fazer), a especialização do gesto técnico de uma determinada modalidade esportiva acaba sendo retardada em nome da garantia da aquisição, por parte do aluno, dos princípios operacionais e das regras de ação das modalidades coletivas. Não se trata de secundarizar as formas eficientes de execução esportiva, mas de colocá-la no tempo correto da aprendizagem, a fim de se evitar, ou o abandono precoce de qualquer forma esportiva devido a frustrações, ou à especialização também precoce de uma única forma, fato tão nefasto quanto o anterior. Os efeitos danosos, frutos da especialização esportiva precoce, têm sido registrados por vários autores. Já se conhecem também pesquisas que apontam atletas de alto rendimento, bem sucedidos que tiveram em sua história de vida experiências motoras amplas antes de se especializarem em uma modalidade (DAOLIO, 2002, p. 101).

Dessa forma, são desenvolvidas duas competências básicas para aprendizagem e consequente prática dos esportes coletivos. A primeira sinaliza para a cooperação entendida como a necessidade do praticante de compatibilizar suas ações aos objetivos do grupo. E a inteligência, compreendida como a habilidade de se adequar às diversas dinâmicas que o jogo proporciona, conseguindo solucionar frequentes problemas que surgem. Assim, são elaboradas potencialidades, tais como "os conceitos de tática individual e tática coletiva, ações coordenadas entre o indivíduo e o grupo, no sentido de uma prática de jogo qualitativamente melhor, tanto por parte da equipe como por parte do indivíduo." (DAOLIO, 2002 p. 100). 
Outra aproximação do modelo pendular com a pedagogia crítico-superadora se refere ao processo de ensino-aprendizagem, que é organizado na forma de ciclos pela pedagogia específica da Educação Física escolar. Segundo os autores,

(...) os conteúdos de ensino são tratados simultaneamente, constituindo-se referências que vão se ampliando no pensamento do aluno de forma espiralada, desde o momento da constatação de um ou vários dados da realidade, até interpretá-los, compreendê-los e explicá-los (COLETIVO DE AUTORES, 2012, p. 23).

A abordagem de ensino exposta no modelo pendular trata o processo ensino-aprendizagem como dinâmico e sequencial. Tal concepção refuta a ideia de que existem faixas etárias pré-determinadas para se aprender algum conteúdo, em convergência com o Coletivo de Autores (2012), que classifica essa maneira de organização curricular como etapista, fragmentada e linear, ou seja, como princípios da lógica formal de aprender os conhecimentos, contribuindo para a formação de um sujeito com uma visão reduzida da realidade, que não consegue realizar sínteses reflexivas em seu pensamento.

Podemos também destacar, como semelhança entre as pedagogias, o fato de a aprendizagem partir sempre da fase de compreensão que o estudante apresenta em relação ao tema abordado, princípio denominado na abordagem crítico-superadora como sociocognoscitivo, que significa que o conteúdo será escolhido de acordo com a possibilidade de apreensão dele pelo estudante.

Outra característica que conecta o modelo pendular e a pedagogia crítico-superadora, refere-se ao entendimento de que o ensino da técnica na forma hegemônica nos esportes coletivos afasta os alunos das aulas, seja por frustrações causadas por dificuldades ou pela possível especialização precoce que as condutas motoras podem desenvolver, gerando um possível desinteresse futuro dos estudantes pelas atividades. Kunz (1994) afirma que seria uma irresponsabilidade pedagógica, por parte de qualquer educador, proporcionar aos alunos vivências negativas, frustrantes e de exclusão por intermédio dos esportes. Assim, a técnica deve ser pensada como instrumento que facilite a própria aprendizagem e a vivência de movimentos significativos para cada sujeito.

Como fundamento da pedagogia crítico-superadora, tendo como referência Saviani (2011), a função social da escola é a da socialização dos conhecimentos sistematizados, logo, o ensino da técnica pela técnica não apresenta o que o Coletivo de Autores (2012) denomina de relevância social do conteúdo, ou seja, trabalhar simplesmente o passe, a finalização ou o arremesso depois de esperar em longas filas, para um estudante que não tem facilidade com esses gestos, não faz sentido e tampouco apresenta significado social e cultural para ele. A técnica, nesse momento, faz com que a escola não cumpra sua função social e age na contramão da aprendizagem.

Mauss (2003), em seu clássico estudo sobre as técnicas corporais, afirma que todo gesto corporal se constitui em técnica, uma vez que é dotado de tradição e de eficácia simbólica. Assim, torna-se uma construção cultural, um símbolo. Desse modo, na Educação Física escolar, historicamente esportivizada, um gesto técnico tido como eficiente tem que ser reproduzido, fazendo com que aquele que não consiga realizar o dito seja excluído e, por vezes, depreciado durante a aula. Contudo, em uma aula fundamentada na abordagem crítico-superadora, a utilização das técnicas trazidas do esporte de alto rendimento não pode exigir a perfeição da execução delas, nem tampouco ser forma avaliativa e, muito menos, se apresentar como a única possibilidade de vivência das destrezas motoras de cada modalidade esportiva.

Ainda, com Mauss (2003), precisamos compreender que os padrões da cultura e os valores de cada sociedade, da mesma forma que as funções sociais que os indivíduos exercem, forjam técnicas corporais peculiares. Nesse sentido, a tradição é outro aspecto fundamental das técnicas corporais, ou melhor, não existe técnica sem tradição, eis a diferenciação primária dos homens dos demais ani- 
Pedagogia crítico-superadora e o modelo pendular:

uma aproximação necessária para o ensino dos esportes coletivos na escola

mais, segundo o antropólogo francês, que é a capacidade de transmissão de suas técnicas de forma oral e tradicional. Sendo assim, o esporte deve ser considerado também como espaço de vivenciais significativas tanto para a aprendizagem das formas técnicas tradicionais de cada modalidade, como para a expressão de novas possibilidades para os gestos motores.

Do mesmo modo, os autores do modelo pendular, segundo Daolio (2002), entendem que esse valor cultural e simbólico que os gestos técnicos apresentam, expressam-se em duas situações. Logo, estão presentes tanto na forma hegemônica da realização dos movimentos, como na forma individual intrínseca de cada sujeito, que é construída culturalmente. Na escola, cabe ao professor realizar essa mediação, considerando o desenvolvimento individual de cada estudante, porém, não tendo como parâmetro de exigência o esporte de alto rendimento. Assim, é tarefa do docente desenvolver também o lado técnico do estudante, contudo de forma gradual e de acordo com o proposto pelo modelo pendular.

Em outras palavras, a técnica deve ser entendida como uma ferramenta necessária para a superação de limites da própria prática social humana. Afınal, as técnicas esportivas são formas de condutas e de ações dos próprios jogos esportivos, são elementos essenciais e constitutivos deles, sendo uma dimensão inalienável da cultura corporal de qualquer estudante em fase de escolarização, pois, nas esteiras de Mauss (2003), fazem parte da experiência humana e se constroem na relação entre o ser humano, a cultura e a sociedade.

\section{CONSIDERAÇÕES FINAIS}

Nesse momento, reafirmamos de forma sintética a relação entre a abordagem mais ampla (cultura corporal) e que direciona o ensino da Educação Física, com a pedagogia voltada exclusivamente para a intervenção nos esportes coletivos. A pedagogia crítico-superadora não se caracteriza como uma "receita de bolo", um manual, nem determina uma didática única para o ensino do esporte. Dessa maneira, o ensino do esporte deve se direcionar por via da mediação do professor, de forma que ele reflita criticamente sobre o esporte hegemônico e, posteriormente, para que tal reflexão seja incorporada pelos estudantes durante o processo de ensino-aprendizagem.

Assim, a pedagogia crítico-superadora entende que o esporte tem que ser desmistificado, criticado e praticado de uma forma que não reproduza os valores da sociedade capitalista. Logo, propõe-se que, por meio de debates e de vivências críticas e significativas, o esporte hegemônico seja superado. Nesse contexto, o modelo pendular se manifesta como uma possibilidade metodológica clara e que pode criar um sentido de coletividade autêntica, o que no Coletivo de Autores (2012) é apenas indicado como necessidade.

Apontamos que essa pedagogia do ensino dos esportes coletivos pode proporcionar, de forma mais avançada, a conexão entre aluno, professor e conhecimento, gerando a apreensão do conhecimento de modo diferente dos modelos tradicionais e tecnicistas e, assim, a nosso ver, completando o sentido da proposta do Coletivo de autores (2012).

Tendo acesso à base estrutural e de funcionamento dos esportes coletivos, o estudante terá a possibilidade de praticar e de entender as diversas modalidades, desenvolvendo tanto valências físicas (que as duas também consideram como importantes para a aula), quanto uma concepção crítica, podendo ter condição para conquistar a autonomia em relação às suas práticas e em seu tempo de lazer.

Dessa forma, assim como o Coletivo de Autores (2012), o modelo pendular tem em seu propósito que "o importante é que o acesso à cultura do esporte coletivo estará assegurado a todos os alunos, independente de sua idade, de sua condição atlética ou de suas habilidades esportivas." (DAOLIO, 2002, p. 101). 
Acreditamos que o estudo realizado necessita ser compreendido como um esforço de sistematizar as proximidades entre as duas pedagogias, e de como o professor de Educação Física que atua na educação básica, na formação de professores ou em outros espaços educativos pode dialogar com essas perspectivas. Por fim, apontamos a necessidade do seguimento das investigações no campo da pedagogia do esporte, assim como a sistematização de práticas e futuros relatos de experiências que utilizem e ressignifiquem o que expomos neste ensaio.

\section{REFERÊNCIAS}

ADORNO, T. Dialética negativa. Rio de Janeiro: Zahar, 2013.

ADORNO, T. Educação e emancipação. Rio de Janeiro: Paz e Terra, 1995.

ADORNO, T. Teoria da semicultura - Parte I. Revista "Educação e Sociedade" n. 56, ano XVII, dezembro de 1996, pág. 388-411.

ALTHUSSER, L. Aparelhos ideológicos do estado. São Paulo: Editora Presença, 1980.

AYUOB, E. Ginástica geral e educação física escolar. São Paulo: Editora da Unicamp, 2003.

ASSIS DE OLIVEIRA, S. A reinvenção do esporte: possibilidade da prática pedagógica. Campinas, SP. Autores Associados, 2001.

BOURDIEU, P; PASSERON, J. C. A reprodução: elementos para uma teoria do sistema de ensino. Tradução de Reynaldo Baião; revisão Pedro Benjamin Garcia e Ana Maria Baeta. 7. ed. Petrópolis: Vozes, 2014.

BOURDIEU, P. Como é possível ser esportivo?. Paris, março de 1978.

BOURDIEU, P. Programas para uma sociologia do esporte. IN: BOURDIEU, P. Coisas ditas. São Paulo: Brasiliense, 2004.

BREGOLATO, R. A. Cultura corporal da dança. São Paulo: Ícone, 2000.

BRACHT, V. A criança que pratica esporte respeita as regras do jogo... capitalista. Revista Brasileira de Ciências do Esporte. V. 7, número 2. 1986.

BRACHT, V. A Educação Física brasileira e a crise da década de 1980: entre a solidez e a liquidez. IN: MEDINA, J. P. S. A educação física cuida do corpo... e "mente": novas contradições e desafios para o século XXI. 26. ed. Campinas, SP. Papirus, 2017.

BRACHT, V. Educação física \& ciência: cenas de um casamento (in) feliz. 4. ed. Unijuí, 2014.

BRACHT, V. Educação física e aprendizagem social. 2. ed. Porto Alegre: Magister, 1997.

BRACHT, V. Sociologia crítica do esporte: uma introdução. 3 ed. ljuí: Unijuí, 2005.

CAMPOS, L. A. S. Didática da educação física. Várzea Paulista, SP. Fontoura, 2011. 
Pedagogia crítico-superadora e o modelo pendular:

uma aproximação necessária para o ensino dos esportes coletivos na escola

CASTELLANI FILHO, L. Pelos meandros da Educação Física. Revista Brasileira de Ciências do Esporte, V. 14, Número 13, Maio/1993.

COLETIVO DE AUTORES. Metodologia do ensino de educação física. São Paulo: Cortez, 2012.

DAOLIO, J. Jogos esportivos coletivos: dos princípios operacionais aos gestos técnicos - modelo pendular a partir das idéias de Claude Bayer. Rev. Bras. Ciên. e Mov. Brasília v. 10 n. 4 p. 99-104 outubro 2002.

ELIAS, N; DUNNING, E. A busca da excitação. Lisboa, Difel, 1992.

GAMBOA, S. S. Epistemologia da educação física: as interrelações necessárias. 2. ed. rev. e ampl. Maceió: EDUFAL, 2010.

GHIRALDELLI, P. Educação física progressista: a pedagogia crítico-social dos conteúdos e a educação física brasileira. 3. ed. Edições Loyola, São Paulo: Brasil, 1991.

GIL, A. C. Como elaborar projetos de pesquisa. 4. ed. São Paulo: Atlas, 2002.

GRAMSCI, A. Os intelectuais e a organização da cultura. Rio de Janeiro: Civilização brasileira, 1991.

HOBSBAWM, E. A invenção das tradições. 10. ed. São Paulo: Paz e Terra, 2015.

KUNZ, E. Educação física: ensino \& mudanças. Ijuf: Unijuf, 1991.

KUNZ, E. Transformação didático-pedagógicas do esporte. Ijui: Unijuf, 1994.

MARX, K. O capital: crítica da economia política: Livro I: o processo de produção do capital. São Paulo: Boitempo, 2013.

MARX, K; ENGELS, F. A Ideologia alemã. São Paulo: Expressão Popular, 2007.

MARX, K. Contribuições à crítica da economia política. 2. ed. São Paulo: Expressão Popular, 2008.

MAUSS, M. Sociologia e Antropologia. São Paulo: Cosac Naify, 2003.

PAIVA REIS, A et al. Pedagogia histórico-crítica e educação física. Juiz de Fora: Editora UFJF, 2013.

SAVIANI, D. Pedagogia histórico-crítica: primeiras aproximações. 11.ed. rev.- Campinas, SP. Autores Associados, 2011.

SEVERINO, A. Metodologia do trabalho científico. São Paulo: Cortez Editora, 2002.

SOUZA, M. S. Esporte escolar. possibilidade superadora no plano da cultura corporal. São Paulo: Ícone, 2009.

STIGGER, M. P. Educação Física, esporte e diversidade. Campinas, SP. Autores Associados, 2005.

THOMAS, R. Histoire du sport. Paris, Universitaires de France, 1991.

TUBINO, M. G. Dimensões sociais do esporte. 3. ed. São Paulo: Cortez, 2011. 